Original Article

\title{
Transfer of the effect of potentized mercuric chloride on $\alpha$-amylase from one test tube to another through capillary water
}

\author{
Atheni Konar, MSc1,3, Tandra Sarkar MSc1,3, Nirmal Chandra Sukul*, PhD ${ }^{2,3}$, Anirban Sukul \\ PhD ${ }^{3}$, Indrani Chakraborty, PhD.,4
}

1Molecular Homeopathy Research Unit, Dr. Bholanath Chakravarty Memorial Trust, Kolkata, West Bengal, India

${ }^{2}$ Department of Zoology, Visva-Bharati University, Santiniketan, WestBengal, India

${ }^{3}$ Sukul Institute of Homeopathic Research, Santiniketan, West Bengal, India

${ }^{4}$ Department of Zoology, Belda College, West Midnapur, West Bengal, India

*Corresponding author: NC Sukul,ncsukul@gmail.com

\begin{abstract}
Objective: In a series of experiments we showed that treatment of a plant or animal with a diluted and agitated substance might affect other plants or animals connected to the former by the capillary water in cotton threads. The aim of the present study was to establish whether drug effect could be transferred in a cell-free medium.

Design: Two test tubes, each containing $1 \mathrm{ml}$ of $1 \%$ starch solution and $1 \mathrm{ml}$ of $\alpha$-amylase, were connected by means wet cotton threads encased in a polythene tube. One of the tubes also contained Mercurius corrosivus (Merc-c) $30 \mathrm{cH}$ and the other ethanol solution (control). After 15 min, the enzyme activity was stopped with DNSA, and the breakdown product of starch, maltose, was estimated. A third, separate tube contained all the tested materials except for Merc-c and the control solution. In a second experiment two tubes, one containing 1,200 ppm and the other 200 ppm of maltose, were similarly connected over $15 \mathrm{~min}$. Both experiments were repeated 20 times.
\end{abstract}

Results: In the first experiment, the amount of maltose was similar in both connected tubes, but it was significantly lower in the unconnected tube. In the second experiment, maltose concentration in both tubes remained unchanged.

Conclusion: The information of Merc-c $30 \mathrm{cH}$ was effectively transferred through capillary water between two tubes in cell-free medium. This effect was not due to physical transfer of either solvent or solutes. Water seems to the most probable carrier of information in diluted and agitated solutions.

Keywords: Water, $\alpha$-amylase, Mercurius corrosivus $30 \mathrm{cH}$, starch, maltose, high dilutions

\section{OPEN ACCESS}

Cite as: Konar A, Sarkar T, Sukul NC, Sukul A, Chakraborty I. Transfer of the effect of potentized mercuric chloride on $\alpha$ amylase from one test tube to another through capillary water. Int J High Dilution Res. 2015;14(1): 4-11. 


\section{Introduction}

In a series of experiments we demonstrated that the effect of diluted and agitated substances was transferred from one plant to another, ${ }^{1,2}$ and also from one animal to another through the capillary water in cotton threads. ${ }^{3,4}$ The studies indicate that water behaves as the carrier of the information contained in homeopathic drugs. To exclude the possible interference of a living body with the transfer of the drug effect, we devised a cell-free model.

In an earlier study, Sukul et $a l^{5}$ found that Mercurius corrosivus (Merc-c) $30 \mathrm{cH}$, accelerated in vitro hydrolysis of starch by $\alpha$ amylase in a cell-free medium. That model was adapted to conduct the transfer experiment in a cell-free medium. Boyd ${ }^{6}$ first reported that Merc-c $30 \mathrm{cH}$ enhanced the in vitro hydrolysis of starch by diastase. Potentized mercuric chloride was reported to increase the $\alpha$-amylase activity ${ }^{7}$. Positive effect of Merc-c $30 \mathrm{cH}$ was also reported in systematic reviews. ${ }^{8,9}$

\section{Materials and methods}

Merc-c 30 cH (Dr. Reckeweg, Germany) was purchased as a $10-\mathrm{ml}$ sealed vial from the local market, Kolkata, India. The drug was prepared in $90 \%$ ethanol as shown in the label. The control consisted of $90 \%$ ethanol was prepared from absolute ethanol (Merck,
Germany). Both control and drug were diluted with sterile distilled water in proportion 1:500 two hours before each experiment. In an earlier study, we established that diluting a homeopathic drug in proportion 1:1,000 conserves the specific efficacy of the drug, while it eliminates the effect of the diluent medium, ethanol. ${ }^{10}$

\section{Preparation of reagents}

DNSA reagent was prepared with $1 \mathrm{~g}$ dinitrosalicylic acid (DNSA), 0.2 g crystalline phenol and 0.5 g sodium sulfite. DNSA was then dissolved in $100 \mathrm{ml}$ sterile distilled water with $1 \% \mathrm{NaOH}$, and stored in the dark at $4{ }^{\circ} \mathrm{C}$. Rochelle salt was prepared with $40 \mathrm{~g}$ potassium sodium tartrate dissolved in 100 $\mathrm{ml}$ distilled water, and then placed in sealed glass vials and stored at $4{ }^{\circ} \mathrm{C}$. Soluble starch (SRL, Mumbai, India) was dissolved in $0.1 \mathrm{M}$ sodium acetate buffer ( $\mathrm{pH} 4.7)$ to prepare $1 \%$ starch solution. Porcine $\alpha$-amylase was obtained from SRL.

The activity of $\alpha$-amylase in terms of maltose release resulting from the hydrolysis of starch was measured by a standard biochemical procedure.5, 12 Maltose is a disaccharide of $\alpha$ 1, 4 linked glucose. ${ }^{3}$ One milliliter of $\alpha$ amylase was mixed with $100 \mu \mathrm{l}$ of Merc-c 30 cH 1:500 or control I (90\% ethanol, 1:500) solution and kept in test tubes. The test tube containing enzyme and drug solution was

\section{OPEN ACCESS}

Cite as: Konar A, Sarkar T, Sukul NC, Sukul A, Chakraborty I. Transfer of the effect of potentized mercuric chloride on $\alpha$ amylase from one test tube to another through capillary water. Int J High Dilution Res. 2015;14(1): 4-11. 
connected by means of a wet cotton thread to another test tube, which contained the enzyme and, instead of the drug, an equal amount of distilled water (Figure 1). A piece of $15-\mathrm{mm}$ thick, $80-\mathrm{cm}$ long sterile cotton thread was soaked in sterile distilled water and encased in a flexible $37-\mathrm{cm}$ long polythene tube so that the free ends of the thread remained uncovered (Figure 1).

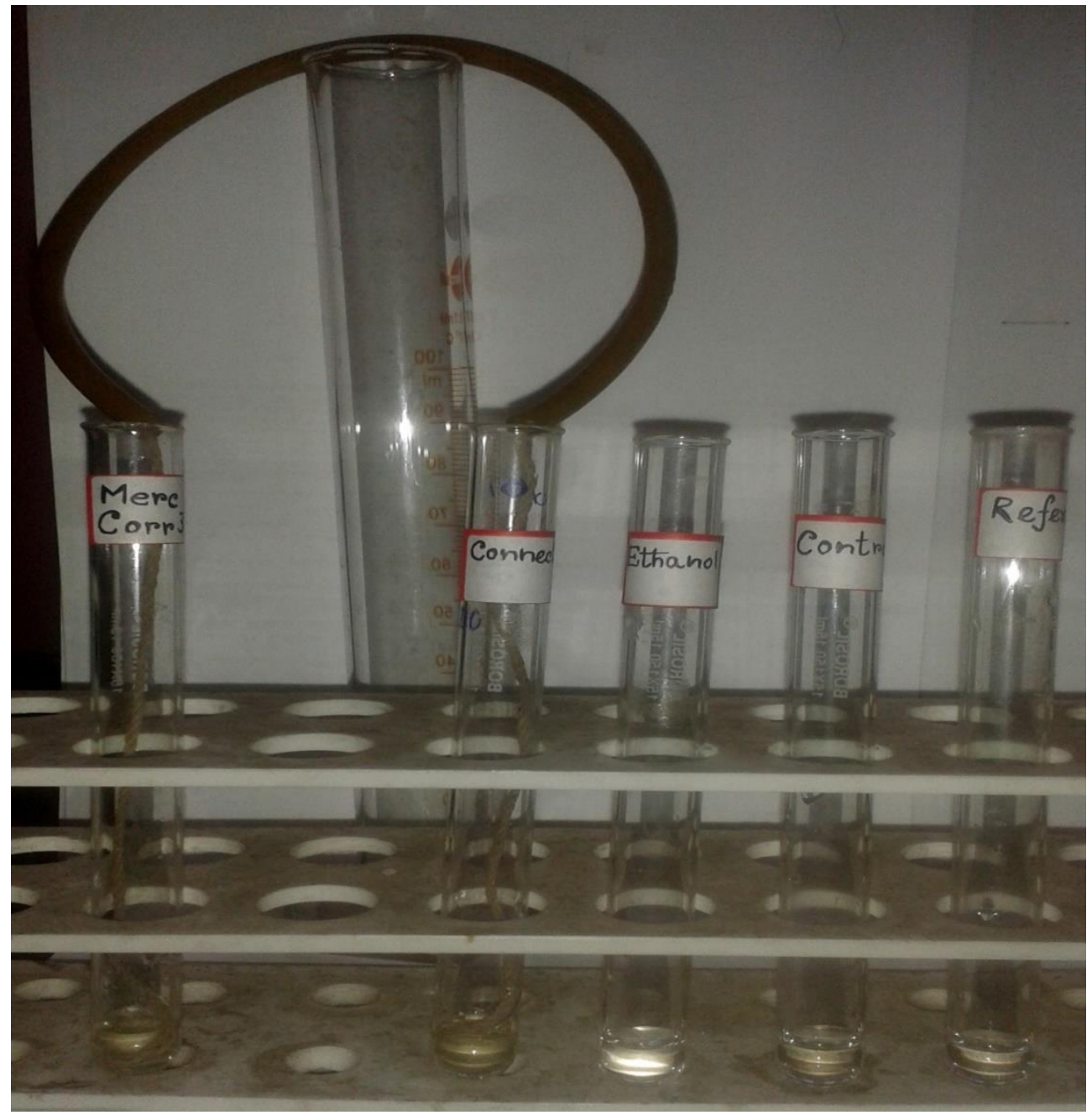

Figure 1. Test tube containing Merc-c $30 \mathrm{cH}$ (far left) connected to a test tube without the drug (second from left). Test tubes containing ethanol control I (third from left) and distilled water control II (fourth from left). Test tube on the far right was used as reference.

Each test tube was $15-\mathrm{cm}$ high and $4-\mathrm{mm}$ wide inside. The experiment included two further test tubes, one containing enzyme and ethanol solution (Control I) and the other enzyme and sterile distilled water (Control II) in the same amount as the drug or control I). Ten min later, $1 \mathrm{ml}$ of starch solution was added to each test tube (the connected pair and controls I and II) and kept for 15 min. The 2 connected tubes were kept at the same

\section{OPEN ACCESS}

Cite as: Konar A, Sarkar T, Sukul NC, Sukul A, Chakraborty I. Transfer of the effect of potentized mercuric chloride on $\alpha$ amylase from one test tube to another through capillary water. Int J High Dilution Res. 2015;14(1): 4-11. 
level for the solution not to move from one to the other through the wet thread. After 15 min, the connecting thread was carefully withdrawn from the paired tubes. Next, $2 \mathrm{ml}$ of DNSA reagent was simultaneously added to each tube to stop the enzyme activity. The 4 tubes were placed in boiling water for exactly 2 min and then cooled to room temperature $\left(27{ }^{\circ} \mathrm{C}\right)$. Next, $5 \mathrm{ml}$ of distilled water were added to each tube. The optical density (OD) of the solution in each test tube was measured at $540 \mathrm{~nm}$ in a UV-VIS spectrophotometer (Shimadzu, Japan). The breakdown product, maltose, was quantified on a standard curve plotted with 6 different concentrations of maltose $(200,400,600$, $800,1,000$ and 1,200 ppm). The experiment was repeated 20 times. To exclude the possibility of direct transfer of solutions between the 2 connected test tubes through the capillary water in the connecting thread we performed another experiment. Two similar test tubes containing maltose solutions of different concentration (200 and $1,200 \mathrm{ppm}$ ) only were connected in a similar manner by means of wet cotton thread. After $15 \mathrm{~min}$, the connecting thread was quickly withdrawn and the concentration of maltose in each test tube was measured in the spectrophotometer. Also the second experiment was repeated 20 times. All the experiments were randomized by changing the relative position of test tubes except the connected ones, and the examiner was blinded as to the test tube contents. The results were analyzed by means of one-way ANOVA. All the experiments were conducted at room temperature $\left(27{ }^{\circ} \mathrm{C}\right)$ and $60 \%$ relative humidity.

\section{Precautions essential for consistent results}

1. The DNSA reagent should be added to the drug containing and connected tubes simultaneously to stop the starch breakdown at the same time.

2. The test tubes should receive uniform heat in the water bath.

3. The cotton thread should remain properly immersed in the test tube liquid and the covering tube should remain upright.

4. Drug and ethanol solution (1:500) should be prepared freshly before each experiment.

\section{Results}

The amount of maltose released following 15min reaction of $\alpha$-amylase with starch in the 4 test tubes is presented with the corresponding standard error and results of statistical analysis in Figure 2.

\section{OPEN ACCESS}

Cite as: Konar A, Sarkar T, Sukul NC, Sukul A, Chakraborty I. Transfer of the effect of potentized mercuric chloride on $\alpha$ amylase from one test tube to another through capillary water. Int J High Dilution Res. 2015;14(1): 4-11. 


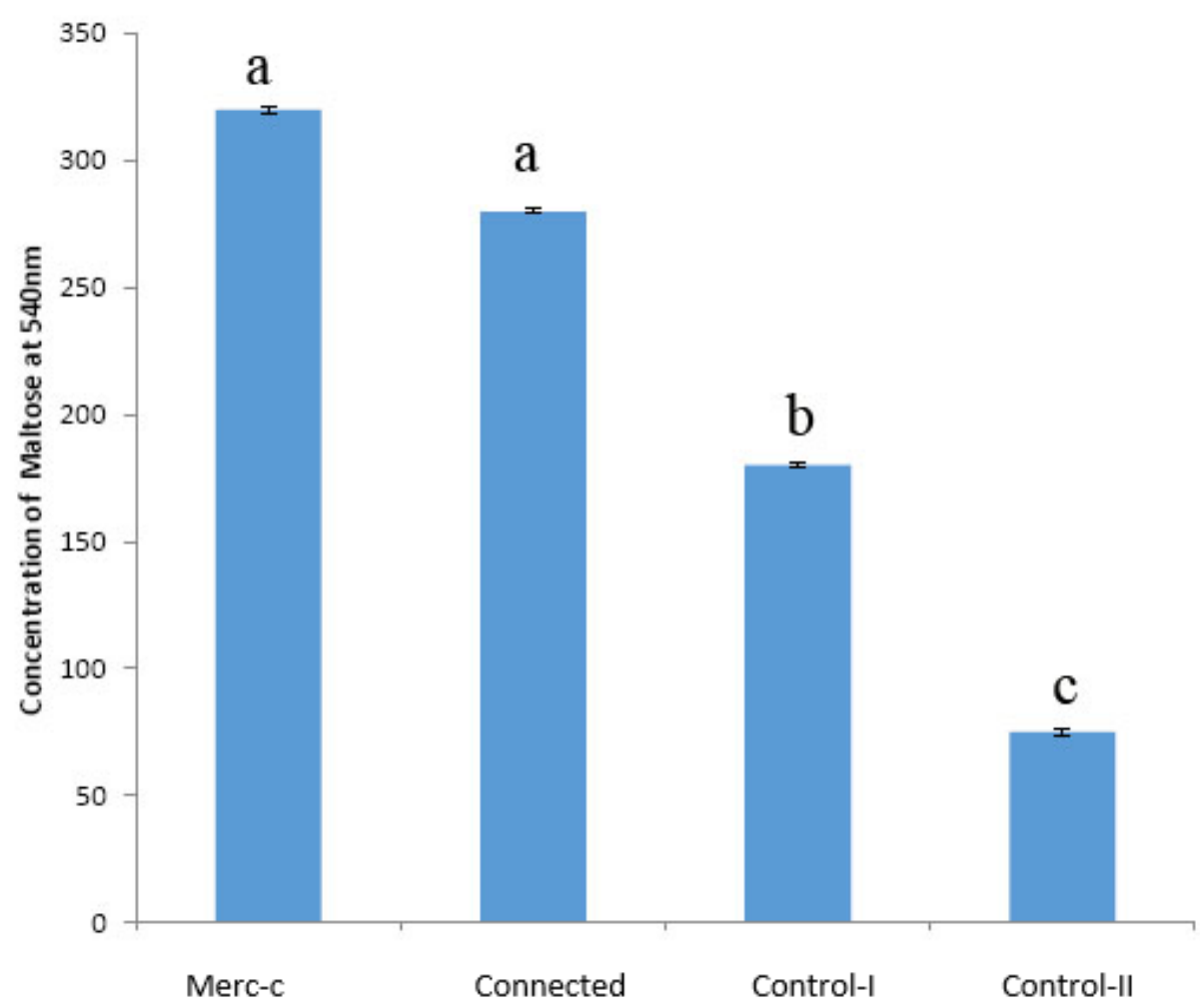

Figure 2. 1. Direct treatment with Merc- $c \mathrm{cH}, 2$. Test tube without Merc- $\mathrm{c} 30 \mathrm{cH}$, but connected to tube $1 \mathrm{I}$ by a cotton thread. 3. Test tube containing diluent ethanol only (Control I). 4. Test tube containing distilled water instead of drug or ethanol (Control II).

$a, b, c$ : different lowercase letters indicate significant difference $(\mathrm{p}<0.01)$ by one-way ANOVA followed by Student's t-test. $\mathrm{n}=20$.

The data were analyzed by means of one-way ANOVA followed by Student's t-test. The amount of maltose in the tubes containing Merc-c $30 \mathrm{cH}$ did not differ significantly from that in the connected tubes $(p<0.05)$. The tubes containing water (Control II) showed the lowest amount, while the ones containing ethanol (Control II) showed a significantly higher value compared to the ones with water $(\mathrm{p}<0.01)$. Both the tubes containing Merc-c 30 $\mathrm{cH}$ and the connected ones exhibited the highest amount of released maltose, which was significantly different compared to the ones containing ethanol $(\mathrm{p}<0.01)$. The results of the second experiment showed that the concentration of maltose solution in the connected pair of tubes remained unchanged after 15 min: the initial and final concentrations were 200 and 1,200 ppm, respectively.

\section{Discussion}

The results provide further confirmation of our earlier results showing that diluted and 
agitated Merc-c $30 \mathrm{cH}$ promotes $\alpha$-amylaseinduced hydrolysis of starch. ${ }^{5}$ However, other authors did not find any effect of Merc-c on

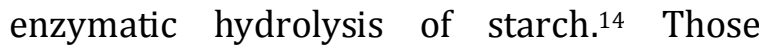
authors prepared Merc-c with distilled water, while the efficacy of a homeopathic drugs diluted in pure water deteriorates quickly.5,6 In addition, aqueous preparations might produce anomalous results. In turn, use of hydrated ethanol is problematic, as it produces some effect of its own. However, the effect of ethanol is substantially minimized by diluting aqueous ethanol in water in proportion $1: 500$ or $1: 1,000 .{ }^{10}$

The results of the present study provide evidence on that water behaves as an effective carrier of the imprint of the starting materials. The results of the second experiment clearly demonstrate that there was no physical transport of solvent (water) or solute (maltose) between the test tubes connected by capillary water. We recently reported that high dilutions of different drugs differ as to their hydrogen bonding and free water molecules. ${ }^{15}$ The present in vitro study once again indicates that water seems to be the most probable carrier of information of the starting materials in homeopathic high dilutions.

\section{Conclusion}

The information of Merc-c $30 \mathrm{cH}$ was effectively transferred through capillary water between 2 tubes in a cell-free medium. That effect was not due to physical transport of either solvent or solute between the tubes. Water seems to be the most probable carrier of the information in homeopathy high dilutions.

\section{Acknowledgements}

The present study was supported by grants from the Sukul Institute of Homeopathic Research. We are thankful to Ms. Amrita Pal, Assistant Professor, B.B. College Asansol, West Bengal, India, for the help with statistical analysis. AK \& TS thank Dr. Bholanath Chakravarty Memorial Trust for their research grants.

The authors declare that there is no conflict of interest.

\section{References}

1. Mondal S, Sukul S, Sukul NC. Transfer of effect of heat shock and drug treatment from one plant to another through water. J Altern Med Res 2012; 4:179-185.

2. Mondal S, Sukul S, Sukul NC, Sukul. Water as carrier of information of heat shock and drug effect between two group of Adhatoda vasica plants. Int J High Dilution Res. [online]. 2012; 11(39):60-68.

OPEN amylase from one test tube to another through capillary water. Int J High Dilution Res. 2015;14(1): 4-11. 
3. Chakraborty I, Sukul NC, Sukul A, Chakravarty R. Transfer of the antialcoholic effect of $\mathrm{Nux}$ vomica $200 \mathrm{cH}$ through water from one group of toads to another under alcohol anesthesia. Int I High Dilution Res. [online]. 2012;11(41):216-223.

4. Chakraborty I, Sukul NC, Sukul A, Chakravarty R. Inter-group transfer of the anti-alcoholic effect of Nux vomica $200 \mathrm{cH}$ through the body of a live toad. Int J High Dilution Res. [online]. 2014; 13(46):03-12.

5. Sukul NC, De A, Sinhababu SP. Potentized Mercuric Chloride and Mercuric Iodide enhance $\alpha$-amylase activity in vitro. Homeopathy 2002; 91(4):217-220.

6. Boyd WE. Biochemical and biological evidence of the activity of high potencies. Br. Hom. J. 1954; 44(1):644.

7. Sabir S, Khan S, Begum S et al. Effect of homeopathic drugs on the in vitro activity of $\alpha$-amylase from human saliva. Ind J Hom 1996; 31:93-98.

8. Endler PC, Thieves $\mathrm{K}$, Reich $\mathrm{C}$, Matthiessen P, Bonamin L, Scherr C, Baumgartner S. Repetitions of fundamental research models for homeopathically prepared dilutions beyond 10-23: a bibliometric study. Homeopathy 2010; 99(1):25-36.

9. Witt CM, Michael B, Albrecht M, Weibhuhn TER, Baumgartner S, Willich SN. The in vitro evidence for an effect of high homeopathic potencies a systematic review of the literature. Compl Ther Med. 2007;15(2):128-138.

10. Sukul S, Mondal S, Sukul NC. Sepia 200 $\mathrm{cH}$ in 1:1000 dilution counteracts the effect of salt stress in cowpea seedlings but vehicle $90 \%$ ethanol proves ineffective in the same dilution. Int I High Dilution Res. [online]. 2012; 11(41):237-240.

11. Sukul NC, Sukul A. High dilution effects: Physical and biochemical basis. Dordrecht: Kluwer Academic Publishers; 2004.

12. Bernfield P. Amylase, $\alpha$ and $\beta$. In: Colowick S, Kaplan NO, editors. Methods of enzymology. New York: Academic Press; 1955, p.149-158.

13. Nelson DL, Cox MM. Lehninger Principles of Biochemistry, $3^{\text {rd }}$ ed. New York: Macmillan Worth Publishers; 2000.

14. Witt CM, Bluth $M$, Hinderlich S, Albrecht $\mathrm{H}$, Ludtke R, Weisshuhn TER, Willich SN. Does potentized $\mathrm{HgCl}_{2}$ (Mercurius corrosivus) affect the

\section{OPEN ACCESS}

Cite as: Konar A, Sarkar T, Sukul NC, Sukul A, Chakraborty I. Transfer of the effect of potentized mercuric chloride on $\alpha$ amylase from one test tube to another through capillary water. Int J High Dilution Res. 2015;14(1): 4-11. 
International Journal of High Dilution Research 2015; 14(1): 4-11 Available online at www. highdilution.org

activity of diastase and $\alpha$-amylase? I

Alt Complement Med 2006; 12(4):359-

$\underline{365 .}$

15. Chakraborty I, Datta S, Sukul A, Chakravarty R, Sukul NC. Variation in free and bound water molecules in different homeopathic potencies as revealed by their Fourier Transform Infrared Spectroscopy (FTIR). Int I

High Dilution Res. 2014; 13(49): 189196.

Received: January 8 2015. Accepted: March 12015.

(C) International Journal of High Dilution Research.

Not for commercial purposes.

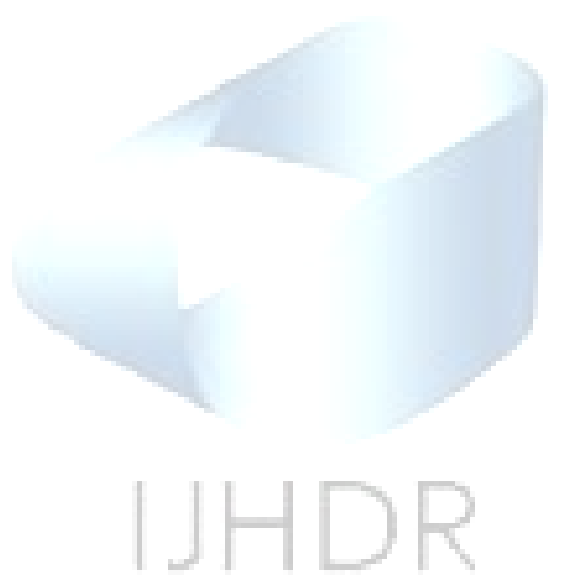

OPEN ACCESS

Cite as: Konar A, Sarkar T, Sukul NC, Sukul A, Chakraborty I. Transfer of the effect of potentized mercuric chloride on $\alpha$ amylase from one test tube to another through capillary water. Int J High Dilution Res. 2015;14(1): 4-11. 